\title{
Violência, delinquência e tendência antissocial. Sobre a experiência de um atendimento a crianças vítimas da violência em uma favela do Rio de Janeiro
}

\section{Violence, delinquency and antisocial tendency. The experience of treating children victimized by violence in a slum in Rio de Janeiro}

La violencia, la delincuencia y la tendencia antisocial. Sobre la experiencia de la asistencia a niños víctimas de la violencia en una favela de Río de J aneiro

\section{Rosa Lucia Soares Paiva*}

Pontifícia Universidade Católica do Rio de Janeiro - PUC-Rio, Rio de Janeiro, Rio de Janeiro, Brasil

\section{Maria Helena Rodrigues Navas Zamora**}

Pontifícia Universidade Católica do Rio de Janeiro - PUC-Rio, Rio de Janeiro, Rio de Janeiro, Brasil

\section{J unia de Vilhena***}

Pontifícia Universidade Católica do Rio de Janeiro - PUC-Rio, Rio de Janeiro, Rio de Janeiro, Brasil

\section{Sergio Gomes da Silva****}

Universidade Federal do Rio de Janeiro - UFRJ, Rio de Janeiro, Rio de Janeiro, Brasil

\begin{abstract}
RESUMO
Considerando nossa inserção em um projeto social realizado dentro de uma favela do Rio de Janeiro, o presente trabalho objetiva analisar os alcances e limites de nossa atuação profissional no atendimento de crianças e adolescentes vítimas de violência e de comportamento antissocial, à luz do pensamento de Winnicott. O projeto objetiva a socialização de crianças e adolescentes vítimas de violência, a partir de atividades circenses, lúdicas, criação de figurinos, aprendizagem de danças e capoeira, acompanhadas por uma equipe de assistentes sociais, pedagogos e psicólogos. O atendimento evidenciou a violência que incide sobre as vidas das crianças e dos adolescentes em suas várias manifestações. Dois estudos de casos são apresentados para ilustrar o trabalho desenvolvido no projeto. Concluiu-se que, malgrado todos os esforços das equipes, que ofereciam um espaço de escuta e acolhimento a esses atores sociais, nem todos puderam encontrar uma saída criativa para suas vidas diante do seu sofrimento psíquico. A possibilidade de construção e reconstrução só foi possível quando estas puderam encontrar no projeto social "Circo" uma "luz no fim do túnel", ou
\end{abstract}


seja, um lugar, um espaço ou "continente suficientemente bom" às suas demandas psíquicas e às da própria vida.

Palavras-chave: infância, violência, tendência antissocial, delinquência, favela.

\begin{abstract}
Considering our insertion in a social program held in a slum in Rio de Janeiro, this work aims at analyzing the range and limits of our professional action in treating children and teenagers victimized by violence and presenting antisocial demeanor, according to Winnicott's thinking. The project aims at the socialization of children and teenagers victimized by violence through activities such as: circus, playing, fashion creation, dancing and "capoeira" practice, while accompanied by a team of social workers, pedagogues and psychologists. The sessions evidenced several manifestations of violence taking place on children and teenagers' lives. Two case studies are presented. The conclusion was that, although all the efforts made by the teams, offering a listening and refuge space to those social actors, not all of them were able to find a creative way out to their lives, in face of their psychological suffering. The possibility of constructing and reconstructing was only possible whenever they could find hope within the social program called "Circus", that is, a place, a space or a "good enough continent" to their psychological demands and of their own lives.
\end{abstract}

Keywords: childhood, violence, antisocial tendency, delinquency, favela (slum).

\title{
RESUMEN
}

Teniendo en cuenta nuestra inserción en un proyecto social llevado a cabo en una favela de Río de Janeiro, el presente trabajo tiene como objetivo analizar el alcance y los límites de nuestra práctica profesional en el cuidado de los niños víctimas de la violencia y el comportamiento antisocial, luz de el pensamiento de Winnicott. El proyecto socializa a los niños y adolescentes víctimas de la violencia, con el: circo, actividades de juego, creación de trajes, bailes de aprendizaje, capoeira y acompañado por un equipo de trabajadores sociales, educadores y psicólogos. La asistencia mostró la violencia que se centra en la vida de niños y adolescentes en diversas manifestaciones. Se presentan dos casos de estudio, se concluyó que, a pesar de todos los esfuerzos de un espacio de escucha y refugio a estos niños, no todo el mundo podía encontrar una salida creativa para sus vidas antes de que su sufrimiento mental. La posibilidad de la construcción y la reconstrucción fue posible sólo cuando se podían encontrar en el proyecto social "Circus" a "la luz al final del túnel", es decir, un lugar o una "buena continente suficiente" a sus demandas psicológicas y la vida misma.

Palabras-clave: infancia, violencia, tendencia antisocial, delincuencia, favelas.

\section{Uma favela carioca e o projeto do circo social}

Durante o período de 2010 a 2013, tivemos a oportunidade de participar de um projeto intitulado "Circo Social" em uma favela do Rio de Janeiro, criado por uma organização não governamental. 0 projeto "Circo Social", que desenvolve o contato com as raízes culturais brasileiras e afrodescendentes, consiste em aulas realizadas 
a partir de um trabalho lúdico, com atividades de criação de figurinos, danças, circo, capoeira e principalmente o atendimento realizado por uma equipe interdisciplinar, composta por profissionais da área de Pedagogia, Psicologia e Serviço Social, além de professores de circo, os quais não somente ministram aulas circenses, mas também já vivenciaram a violência promovida pelo tráfico de drogas.

Nas aulas circenses, a idade mínima para o ingresso é de seis anos, sem limite para a máxima, com a possibilidade de receber bolsa auxílio e "cachês" em dinheiro pelas apresentações. Para participar do Projeto, as escolas e entidades parceiras encaminham crianças e adolescentes, não raro com a indicação de que são "casos perdidos", mas também se aceita demanda espontânea. Entendemos que o conjunto do trabalho criativo de acolhimento emocional que o projeto oferece, com suas atividades de circo e atendimento realizado pela equipe social, cria um contraponto ao cenário da violência imposta às favelas.

Os psicólogos inseridos no "Circo Social" realizam intervenções terapêuticas individuais, em grupo e com as famílias das crianças e adolescentes do projeto, com o objetivo de dar suporte emocional e um lugar de escuta clínica às vicissitudes que estas crianças e adolescentes vivenciam no seu dia a dia. A equipe de serviço social acompanha a inserção dos jovens no projeto, por meio de visitas domiciliares, orientando as famílias no que se refere à garantia dos direitos das crianças e adolescentes, auxiliando, assim, o trabalho psicossocial e clínico. Os pedagogos além de acompanharem o trabalho junto às escolas e professores, também são responsáveis pela inserção das crianças no circo social.

Assim, o trabalho no circo e o atendimento psicoterapêutico, somados ao trabalho da equipe social, têm como objetivo possibilitar uma vida pautada na criatividade das crianças e adolescentes a partir da sua (re) inserção social.

Quando as crianças estão nas aulas de circo, elas recebem amparo dos professores, que em momentos de conversa com o grupo ou mesmo individualmente, passam suas experiências de como conseguiram superar as adversidades de viver sob o jugo do tráfico e da violência que ele promove. É um movimento de troca de experiências e de estímulo para essas crianças, que possuem em tenra idade sofrimentos emocionais avassaladores, comuns até certo ponto, para todos os que moraram ou ainda moram naquele morro.

O morro fica em um bairro turístico da Zona Sul da cidade, cujos primeiros barracos foram construídos nos anos 1930. Atualmente, esta é uma das favelas que passa pelo processo de pacificação, promovido pela Secretaria de Segurança Pública, por meio das Unidades de Polícia Pacificadora (UPPs). Segundo a Secretaria, a finalidade básica das UPPs é a retirada do tráfico de drogas ilícitas, a promoção da paz e o fim da violência. 
O presente trabalho visa analisar, à luz da teoria do desenvolvimento maturacional infantil de Winnicott e a partir do estudo comparado de dois casos clínicos: o comportamento antissocial e delinquente de um adolescente e de uma criança, ambos moradores de uma favela localizada na Zona Sul da cidade do Rio de Janeiro, participante do "Projeto Circo Social" a1 em uma instituição não governamental.

\section{Violência, violências}

Crianças e adolescentes moradores de favelas, não raro, são considerados em termos dos problemas que apresentam ou podem vir a apresentar. São atingidos por uma lógica de criminalização histórica, de controle da população jovem e pobre (Batista, 2003), que "sobra" nos planos para o desenvolvimento econômico. Existe uma crença bastante difundida no Rio de Janeiro, na qual se pressupõe que as favelas sejam o território da violência e que a população ali residente seja, no mínimo, conivente com os traficantes de drogas (Machado da Silva \& Leite, 2007). O sucesso das políticas fundamentadas na lógica da criminalização da pobreza se ancora, em grande medida, na produção de medo e na crença de que os moradores de favelas têm uma natureza violenta.

Contudo, a violência é aqui compreendida como as inúmeras formas de violação de vários direitos humanos. Sociedades desiguais, que mantêm a pobreza e outras formas de opressão, são sociedades estruturalmente violentas. Para Silva (2009), a violência envolve tanto o caráter econômico - da estrutura, ideológicos, quanto de superestrutura, uma vez que a ação violenta se dá no plano material, mas se utiliza da ideologia para legitimá-la socialmente. A falta de equipamentos sociais básicos, a exposição a grupos armados e a ação policial truculenta são exemplos de uma violência provinda ou consentida pelo Estado. Legitima-se, no mais das vezes, uma cultura da violência, do preconceito ou discriminação, que desqualifica moral e subjetivamente negros, pobres, moradores de favela, índios, velhos, mulheres e homossexuais, que sofrem dia a dia por suas diferenças (Silva, 2003, 2010a, 2010b).

Espancamentos, agressões verbais e negligência passam a ser naturalizados pela criança na convivência com grupos violentos. Quando os maus-tratos são vivenciados também em casa, a criança pode ser atraída pelo tráfico, enxergando os traficantes como pais, que "cuidam" delas. As crianças são incumbidas de funções específicas e remuneradas por "esse trabalho", tão atraente quanto mortífero, considerado uma das piores formas de trabalho infantil.

Com a entrada da UPP na favela, o poder da polícia é sustentado pela legitimidade do Estado. Burgos, Almeida, Cavalcanti, Brum e Amoroso (2011) pontuam que uma concepção de polícia que adentra 
a favela para exterminar o inimigo continua a causar desconfiança na população que ali reside. Continua a metáfora de guerra contra os traficantes (Moreira \& Evason, 2013). É uma continuidade "no subconsciente do campo de concentração, enquanto não se considerar obrigatória à participação dessas populações no traço do seu cotidiano e do seu destino, é seguir girando em um círculo vicioso" (Rios, 2012, p.50).

Os lugares aonde crianças vivem e estudam, ou seja, seus territórios subjetivos, são fatores importantes em suas produções subjetivas. As crianças e adolescentes vivem na pele a exclusão por morarem nesse espaço físico, e por serem quem são, o que inegavelmente constitui uma fonte de sofrimento psíquico. A possibilidade de que essas crianças sejam mortas ou feridas em trocas de tiros na favela, apreendidas por policiais, confundidas com marginais ou até mesmo por estarem envolvidas no tráfico e por isso sofrerem maus-tratos, é fortemente presente (Vilhena, Bittencourt, Zamora, Novaes \& Bonatto, 2011).

\section{0 comportamento antissocial e a delinquência em Winnicott}

Em 1939, Winnicott foi chamado para trabalhar como consultor psiquiátrico do governo inglês, atendendo crianças separadas de suas famílias durante os bombardeios oriundos da Segunda Guerra Mundial. Esta experiência da guerra teve um efeito profundo em Winnicott (2011), porque enfrentou a confusão gerada pela desintegração maciça da vida familiar dessas crianças, e também vivenciou o efeito da separação e da perda - da destruição e da morte. Durante este trabalho, teve a oportunidade de trabalhar com crianças denominadas difíceis. Acompanhou 285 crianças, tendo sido a maioria delas observada num período de vários anos. Tratava-se de uma experiência com crianças evacuadas de seus lares em Londres, sob um intenso bombardeio e enviadas para o interior da Inglaterra. Durante todo esse percurso, Winnicott formulou teorias importantes para a psicanálise infantil, entre elas, o desenvolvimento emocional primitivo, as fases do desenvolvimento, os processos do desenvolvimento, a tendência antissocial, a deprivação, a privação e o comportamento delinquente (Winnicott, 2000c).

$\mathrm{Na}$ teoria do desenvolvimento, Winnicott compreende que no início de sua vida, o bebê ainda é completamente dependente em termos de necessidades físicas, corporais e emocionais do seu primeiro ambiente acolhedor, a mãe. Para tanto, a mãe precisa desenvolver uma simbiose com o seu bebê por meio de uma "preocupação materna primária" (Winnicott, 2000b), ou seja, ela precisa vivenciar tudo o que o bebê vivencia em termos físicos, corporais e emocionais. Os cuidados fornecidos ao bebê devem se constituir por ambiente de 
confiança e proporcionados pela mãe em termos de sustentação de suas necessidades (holding) e do manejo dispensados ao bebê (handling). Neste sentido, a mãe se constitui como uma mãesuficientemente boa na medida em que ela se torna esse continente no qual o bebê precisa mergulhar para ter suas necessidades atendidas pelo ambiente materno. Esta é a fase que marca a dependência absoluta.

Na fase seguinte, a dependência relativa, a criança não é totalmente dependente da mãe e passa a distinguir entre um "eu" e um "nãoeu", envolvendo cinco importantes fatores que estão na verdade interligados: a falha gradual da mãe e sua adaptação como resposta ao desenvolvimento apresentado pelo bebê; o início da compreensão intelectual por parte do bebê; a apresentação resoluta e confiante do mundo pela mãe ao infante; o aumento da confiabilidade do bebê em relação à sua própria dependência e a capacidade do bebê de se identificar (Abram, 2000; Winnicott 2000a).

Finalmente, quando tudo ocorreu bem nas etapas anteriores, o bebê pode ir rumo à independência, sem ter vivenciado falhas no ambiente que pudessem ter impedido um desenvolvimento saudável. Este é o momento da criança desenvolver a sua verdadeira independência, sendo capaz de viver uma existência pessoal satisfatória, numa realidade externa cada vez mais complexa. É o momento da socialização e da vivência de relações triangulares em termos afetivos e emocionais (Winnicott, 1983a).

Para Winnicott (1983a), a agressividade é compreendida como parte da expressão primitiva do amor, ou seja, ela é indissociável do amor. Ele a considera inerente à natureza humana, desempenhando um papel fundamental no estabelecimento do contato do bebê com a realidade externa; tanto na distinção entre o eu e o não eu, bem como no reconhecimento do outro como distinto dele próprio. Para o autor, a agressividade está sujeita a várias vicissitudes: à proporção que o bebê cresce, ela será experimentada através de processos totalmente dependentes do tipo de ambiente em que o bebê vive. Os impulsos amorosos primitivos, ou "amor boca", possuem em sua essência a agressividade e a destrutividade (Winnicott, 2000c, p.97). Winnicott (2000c) afirma que os impulsos de amor primitivo têm um aspecto destrutivo, mas não há na criança a intenção de destruir. É importante que façamos a distinção entre o amor primitivo e a tensão instintiva. No amor, são as formas de gestos e contatos que possibilitam ao bebê obter a satisfação, assim como, poder expressar o alívio da tensão instintiva. Na tensão instintiva, o bebê busca a satisfação, que precisa ser saciada a qualquer preço. É importante ressaltar que a qualidade destrutiva do impulso instintivo não tem a ver com sentimentos de ódio e nem de raiva, que é oriunda dos sentimentos de frustração do bebê no encontro com o meio ambiente. Quando tomado por seu impulso excitado, o bebê irá amar 
a mãe com um "amor boca", o amor que devora, consome e machuca.

A agressividade, portanto, cria o mundo e também a destrutividade, e não pode ser categorizada como saúde ou doença e, sim, como um deslizar entre saúde e doença. A agressividade destrói o mundo real, dependendo dos olhos de quem a vê, mas também cria a possibilidade de existir. De um descobrir e não descobrir o mundo surge o bebê-sujeito, rumo à individuação, desde que o objeto sobreviva a seus ataques (Vilhena \& Maia, 2002).

Quando o bebê já experimentou um ambiente acolhedor, durante a fase da dependência absoluta, as falhas maternas são constituídas como defesas que são organizadas contra essas falhas, em termos de privação. Neste caso, o bebê experimenta o caos sob forma de agonias impensáveis, característico da psicose (Winnicott, 1978a, 1978b, 1978c,1994). Quando a mãe falha na fase seguinte, o bebê experimenta um estado defensivo diferente: a deprivação (deprivation) ${ }^{a 2}$, ou seja, uma perda do ambiente acolhedor já experimentado pelo bebê, que traz, consequentemente, um conjunto de comportamentos que o autor denominou de tendência antissocial (Winnicott, 2000b).

Segundo Winnicott (2000b), a tendência antissocial pode ser encontrada em qualquer pessoa, seja ela dita normal ou não. Ela é a expressão vinculada à deprivação vivida durante a fase da dependência relativa, ou seja, trata-se de uma falha ambiental em termos da continuidade dos cuidados à criança. O comportamento antissocial (agressividade, roubo, enurese noturna, violência, etc.) é um pedido de socorro que a criança faz em termos comportamentais, compreendido pelo autor como um sinal de esperança de que o indivíduo venha a redescobrir aquela experiência boa vivida na dependência absoluta e que foi perdida na dependência relativa. $O$ comportamento antissocial aparece em casa ou num contexto mais amplo, tal como na escola ou nas relações sociais da criança.

Portanto, quando Winnicott (2000b) refere-se ao comportamento antissocial que não foi tratado, ele quer enfatizar tanto a possibilidade da esperança e criatividade quanto a importância da restituição de um lar suficientemente bom na constituição do sujeito, sublinhando sempre que essa falha terá a delinquência como consequência. Para ele, mesmo que essas crianças consigam reviver o momento de desapossamento, ficarão sempre com um resto com o qual terão de lidar ao longo de suas vidas (Winnicott, 2000a). Para o pediatra e psicanalista inglês, esta é a expressão da esperança que algumas crianças ainda mantêm dentro de si, uma crença ou crédito da criança no meio, entendendo-se essa esperança como um movimento vindo do meio em relação à criança, curando-a de sua deprivação. De acordo com Bogomoletz (2008), adeprivação é considerada como a perda abrupta de algo que era sentido como 
bom. Por contraste, o que Bogomoletz (2008) chama de "privação" refere-se a uma situação em que a falha do ambiente era constante e começou bem mais cedo. Como a onipotência está ainda em pleno vigor, a falha é sentida como sendo do próprio bebê.

A deprivação ocorre geralmente por volta dos quatro ou cinco anos de idade. Segundo Vilhena e Maia (2002), Winnicott vê neste tipo de ato, a busca de um limite e de um acolhimento, demonstrado neste endereçamento, expresso pelo comportamento antissocial. Portanto, quando falamos de comportamento antissocial que não foi tratado, referimo-nos à esperança e criatividade. Winnicott (2005) em um texto seminal intitulado "Privação e Delinquência" foi enfático quanto à importância de um ambiente acolhedor ou um lar suficientemente bom na constituição do sujeito e, sublinha sempre que essa falha terá a delinquência como consequência no comportamento das crianças e adolescentes.

O psicanalista inglês afirma que o comportamento de uma criança delinquente difere do de uma criança com tendência antissocial, pois na delinquência já haveria defesas constituídas, com ganhos secundários, que dificultariam a criança poder entrar em contato com sua desilusão inicial (Winnicott, 2006).

Como se manifesta esse comportamento antissocial? Segundo o autor, uma criança que rouba açúcar está procurando a boa mãe de quem ela tem o direito de tirar toda a doçura. Quando a criança rouba fora de casa, ela ainda está procurando a mãe, e ao mesmo tempo a autoridade paterna, figura que poderia colocar um limite no seu comportamento impulsivo. Winnicott afirma que na delinquência inteiramente desenvolvida, o que está presente é a busca da atenção da presença de um pai rigoroso, severo, que proteja a mãe quando ela for encontrada. O roubo seria o exemplo típico dessa necessidade imperiosa de chamar a atenção da figura do pai. Os atos antissociais, como a enurese noturna e o furto, indicam que pode haver esperança. Esperança da possibilidade da existência de uma mãe suficientemente boa. Winnicott (2005) nos aponta que até na raiva podemos ver uma indicação de esperança. A criança é uma unidade e é capaz de sentir o choque entre o que é concebível e o que realmente é possível de ser encontrado no que chamamos de realidade compartilhada. Quando uma criança rouba, ela deseja não o objeto roubado, mas sim o que ele contém de referência ao desejo de receber da mãe o que não lhe foi dado.

\section{As Vicissitudes de Paulo e J onas}

Paulo foi encaminhado, com seis anos de idade, para o Projeto do Circo pela escola, por ter um comportamento agressivo; para suas professoras ele era a "criança sem conserto". O encaminhamento se 
deu porque dentro do projeto existe o serviço de psicologia, para o qual a Escola encaminha os alunos que demonstram algum indício de comportamento antissocial com seus pares ou mesmo em casa. Essa avaliação é feita dentro da própria Escola. A avó materna de Paulo foi a única referência de família que a escola encontrou, mas por ser idosa, não participava das atividades escolares.

A mãe de Paulo, Adriana, soube que estava grávida quando estava na cadeia. Ela pouco se alimentava e, em dia de visita, não mantinha uma comunicação satisfatória com o esposo e a sogra. Paulo nasceu com complicações respiratórias, permanecendo internado por duas semanas. Sua mãe continuava presa, tendo ficado quase seis meses sem poder vê-lo, já que o pai o trouxe para casa com menos de um mês de nascido, segundo dizia, ajudado por seus contatos na polícia. Adriana não pôde amamentá-lo, porém, pediu que fosse registrado com o mesmo nome do pai para homenageá-lo, no que foi atendida.

A criança recebeu do pai carinho, atenção e cuidados até os três anos de idade. Segundo sua avó, isso deixava os moradores da favela admirados, posto que o pai era reconhecido por sua crueldade, pois tinha a incumbência de cobrar dos compradores de drogas o dinheiro que deviam. Aos três anos, Paulo foi conduzido pelos traficantes para ver seu pai ser morto, cortado por saraivadas de balas. Eles lhe avisaram que prestasse atenção para nunca repetir o erro de seu pai, considerado delator. O corpo foi jogado em local de desova de cadáveres. Malgrado o pai tenha sido morto de forma violenta, reiteramos que o ambiente acolhedor que Paulo teve até os três anos de idade foi constituído na figura do pai. Ou seja, foi ele quem se constituiu como um ambiente suficientemente bom para a criança até essa idade, antes dela assistir ao pai ser morto pelos traficantes. Dito em outras palavras, a "função materna" foi exercida, neste caso, por um homem.

No primeiro dia de seu atendimento psicoterápico individual a criança chegou questionando o porquê de estar indo em um "médico de gente maluca". As sessões de psicoterapia sempre eram remarcadas, pois Paulo não comparecia, e quando ele vinha, o estímulo mais interessante era dizer-lhe que faríamos trabalhos no computador. Mesmo com toda a dificuldade, Paulo era afetuoso, abraçando a terapeuta constantemente, fazendo da transferência um meio facilitador para que começasse a se sentir acolhido e, aos poucos, apresentasse mudanças em seu comportamento - visto por todos o que conviviam com ele como "uma criança difícil".

A escola para Paulo era considerada um lugar de maus-tratos, o que o desestimulava a continuar estudando e fomentava seu desejo de aprender coisas que as pessoas ensinavam na rua, tais como: limpar carros ou dançar na praia em troca de dinheiro. A forma como era tratado por pessoas de fora da família era considerada por ele como carinhosa, uma vez que em sua casa não havia vínculos afetivos. A 
partir dessa exposição sobre a falta ou escassez de vínculos amorosos na família, a equipe de assistentes sociais foi à casa de Paulo, mas nunca encontrava sua mãe. A avó apenas se limitava a dizer que não se meteria em "confusão entre mãe e filho". Quando chamadas depois das tentativas de visitas à casa realizadas pela equipe, nenhuma das duas comparecia.

À medida que as sessões ocorriam, Paulo mostrava um cuidado extremo com os brinquedos. Dizia que tinha que mantê-los intactos para que não se perdessem ou quebrassem, o que entendemos ser uma tentativa de reparação em busca de uma vida mais saudável. Gostava de massinhas de modelar e desenhos e, por um bom tempo, brincava de família na "casinha de bonecas", cuidando para que eles não se perdessem ou fossem machucados por alguém, pois "os machucados que as crianças recebem ficam na cabeça delas para sempre".

Por mais de seis meses, Paulo conseguiu assumir um comportamento de vitalidade e suas idas da escola para o Circo eram diárias, buscando a terapeuta para ficarem próximos, já que o trabalho desempenhado pela terapeuta consistia em acompanhamento terapêutico individual aos atendidos no projeto. Sua conduta na escola melhorou muito depois que Paulo aderiu às atividades propostas pelo Circo, bem como, o interesse e vinculação positiva com seu processo terapêutico. Certa vez, chegou a levar flores para a terapeuta, dizendo que elas não poderiam nunca murchar, pois representavam o amor dele por ela e pelo Circo.

A certa altura, depois de quase um ano de atendimentos psicoterápicos, a família de Paulo decidiu sair da favela por quase dois meses sem avisar à Escola ou ao Projeto. A avó parecia temer pela segurança da família. Quando a criança retornou, começou a sair com outros meninos e meninas para saquear bares ou executar pequenos furtos a turistas. Seu atendimento passou a ser inconstante. Ele decidiu sozinho recomeçar as atividades do Circo, mas não ia à Escola, e quando o fazia, era expulso por mau comportamento. Este foi o motivo de uma suspensão por uma semana, mesmo após a intervenção da equipe social junto à Direção da Escola.

Da segunda vez que a família saiu da favela, também sem dar explicações, Paulo já não retornou ao atendimento psicoterápico e tampouco ao Circo. Paulo agora se intitulava Paula, informação essa obtida através das pessoas que conheciam Paulo da favela, exibindo um comportamento feminino, aos nove anos de idade, usando roupas de mulher, maquiagem e cabelo com enfeites. Esse afastamento foi marcado por uma ruptura não apenas da aliança entre a psicoterapeuta e o paciente, mas entre Paulo e a possibilidade de dar continuidade à sua vida criativa no Circo, ou seja, uma vida de possibilidades de melhora através das atividades circenses e do 
acompanhamento psicoterápico e social do projeto. Agora ele andava com meninas e dizia ter um namorado mais velho. Todas as tentativas, ao todo seis delas, mediadas pela equipe social de trazê-lo para atendimento foram frustradas, pois dizia que não precisava de "tia" alguma para conversar, agora tinha seu próprio "homem" a3 que fazia isso para ele. Hostil, em seu último contato, ou vinda ao circo, falou com a equipe social do projeto que se encontrava na sala de atendimento social, e fez perguntas tais como as que visavam saber se sua psicóloga e a assistente social gostavam dele "assim mesmo", o que foi afirmado e de pronto solicitado seu retorno tanto às atividades do circo, como à psicoterapia, mas sem sucesso. Paulo não voltou, mas era visto andando pela favela com outras meninas e meninos, e quando não, no entorno da favela praticando furtos e roubos ${ }^{a 4}$.

O segundo caso clínico refere-se a Jonas, que permaneceu em atendimento psicoterápico pelo período de três anos. Ele chegou encaminhado pelo serviço de saúde do posto médico localizado no centro da favela e levado pela vizinha. Jonas é o mais velho dos dois filhos do casal Carla, de 35 anos e Adailton, com 40. Quando Jonas nasceu, Carla não conseguia cuidá-lo de forma adequada, ele chorava muito e quando a mãe tentava dar o peito, o menino não conseguia "pegar". Muitas vezes, Carla sentia-se mal por conta da diabetes, que desenvolveu quando grávida, e não conseguia chegar até o berço de Jonas. Falou que ninguém a ajudou a cuidar de seu primeiro filho e que tudo ficava mais complicado com sua doença, pois teve uma de suas pernas amputadas em decorrência da doença, não podendo mais trabalhar.

Quando Jonas era ainda recém-nascido, seu pai o levava de casa para a rua por achar que ele era muito mimado pela mãe. Carla, por outro lado, tinha medo de perguntar onde Adailton o levava com medo das agressões que sofria, apesar de confiar nele como pai. Certa vez, ao chegar em casa alcoolizado e encontrar Jonas chorando muito, Adailton tentou afogá-lo em um tanque, sendo impedido pelos vizinhos. Devido à escassez de trabalho e do seu alcoolismo, as brigas e agressões entre o casal passaram a ser frequentes.

Segundo a mãe, Jonas sempre foi uma criança muito calada, arredia ao contato, brincava sozinho e gostava de quebrar os poucos brinquedos que tinha. Não gostava que o chamassem de "Doquinha", apelido derivado do apelido de seu pai "Doca". Sempre disse que não era como o pai e não se parecia com ele, pelo contrário, era fisicamente parecido com sua mãe. Aos 11 anos, já media um metro e setenta de altura, o que facilitou sua entrada no tráfico, como soldado, portando arma no morro e em casa. Nesse período, o dinheiro não faltava e a família, antes vivendo no limite da sobrevivência, agora recebia gás, comida e medicações para sua mãe. As agressões acabaram quando J onas expulsou seu pai de casa, 
dizendo que ele nunca mais tocaria em sua mãe e em sua irmã tornando-se, naquele momento, o chefe da casa.

Carla dizia que não sabia como ser amorosa com seu filho, apesar de temer que fosse morto quando ocorriam guerras entre os traficantes ou com a polícia. No tráfico, ele passou a andar com roupas caras, mas não podia sair do morro. Ao mesmo tempo em que o tráfico o acolhia também o aprisionava: ele não podia estudar, não tinha amigos fora do tráfico e não podia sair da favela, sob a ameaça de ser morto.

No início do tratamento psicoterápico, Jonas era muito arredio, pouco falava e demonstrava irritação e desconforto por estar na presença de uma psicóloga numa sala com aspecto muito infantil. Apareceu para seu primeiro atendimento acompanhado da vizinha de onde morava com a família, e daí em diante, sozinho. Procurava sempre estar sentado ou, às vezes, deitado nas poltronas, mantendo-se calado e observando com certa distância todos os brinquedos, preferindo ficar lendo. Sempre muito desconfiado, chegou a perguntar o motivo de estar sendo obrigado a fazer psicoterapia. Ao ser explicado que não havia obrigação, tentamos oferecer um espaço de acolhimento, o que o fez vir às sessões. Malgrado falasse pouco, não faltava. Durante os atendimentos, Jonas ficava muito agressivo quando mencionávamos seu trabalho no tráfico local, parecendo buscar formas de dizer que se sentia protegido e acolhido na boca de fumo. Certa vez, trouxe uma arma, exibindo-a, gerando um desconforto em toda a equipe que 0 atendia. A equipe nesse momento chegou a questionar a possibilidade de encerrar seu atendimento.

Quinze dias após faltar ao último atendimento, chegou em um horário diferente, informando que não queria ter faltado, mas o gerente da boca o havia designado a ficar durante todo o dia em rondas, precisando fugir para vir às sessões. Foi nesse momento que ele passou a permitir que a psicoterapia começasse a ter espaço em seu mundo interno. Decorrente do seu trabalho no tráfico, Jonas era atendido nas sessões terapêuticas, "conforme a demanda", ou seja, sem dias marcados (Winnicott, 1987).

Sua saída do tráfico, por escolha própria, se deu por meio de uma mediação entre o projeto e o tráfico local, para que nem ele nem sua família fossem punidos. Toda a mediação foi acompanhada por ele, o que permitiu a maternagem por parte de sua mãe, sob forma de proteção, carinho e amor, fazendo com que J onas soubesse o que era ser "um menino feliz".

Aos 13 anos, Jonas foi chamado para participar do Projeto, recebendo uma bolsa de participação, com a condição de voltar a estudar. A família (mãe e irmã) foi acompanhada pelo serviço de psicologia em atendimentos familiares e pelo serviço social. O acompanhamento com a família pelo serviço de psicologia ocorreu durante três anos - o 
pai não compareceu a nenhum atendimento com a família. Os atendimentos à família se davam uma vez por semana, durante os três anos de atendimento de Jonas. A mãe, que no começo manteve um discurso muito empobrecido de afetividade, pôde expressar-se ao dizer para Jonas que ele era uma pessoa importante em sua vida, pois a amava e lhe dava paz.

\section{Uma luz no fim do túnel: a esperança como laço social}

Paulo, nos atendimentos, lembrava

"eu sempre fui assim tia, ninguém pode comigo (...)", "a vida é minha e eu faço dela o que eu quiser", (...) "eu pego mesmo tia, tudo otário os turistas, é facinho, eu sou do morro, tudo otário lá embaixo." No caso de Jonas, "eles me tratam como homem tia, eu sou um homem e não um menino" (...); "eu vou cuidar da minha mãe e da minha irmã, lá na boca a gente é tudo soldado, tudo irmão" (“...)". "Eu gosto dos meus tios de lá (tráfico), porque eles gostam de mim".

O pedido de socorro, ou seja, a delinquência aparece quando Paulo retornou à favela e começou a se juntar com outros para roubar, ou quando Jonas disse:

“o tráfico é bom tia, eu gosto, porque lá eu sou respeitado como homem, eu sou um homem e lá ninguém quer saber se eu só tenho 12 anos. Meu pai rouba dinheiro da minha mãe, o dinheiro que é para alimentar minha irmã e minha mãe. Tia, eu não posso deixar isso não, tenho vontade de matar ele".

Ambos têm suas vidas atravessadas pela violência de tal maneira que não conseguem se diferenciar dela. São crianças carentes de uma provisão ambiental adequada na segunda fase do seu desenvolvimento e ambos, em algum momento, vivenciaram situações de deprivação. De igual modo, ambos os casos descritos tiveram como categoria proximal a violência que viveram em idades precoces, e apresentaram, em consequência, comportamentos antissociais e delinquentes. Não obstante a vida em meio a episódios de violência no início da primeira etapa da vida, essas crianças tiveram algum tipo de acolhimento e provisão ambiental na fase da dependência absoluta - mesmo que precário, tendo cuidados físicos e emocionais sustentados por uma função materna (no caso de Paulo, pelo pai até os três primeiros anos de vida; no caso de Jonas, pela mãe, mesmo que doente e em condições precárias). Por isso, as frustrações pelas quais essas crianças passaram em fases bastante 
primitivas de suas vidas foram revividas no seu processo terapêutico, por meio de regressão à dependência e que precisaram ser sustentadas pela psicoterapeuta.

No caso de Paulo, houve descontinuidades importantes, que 0 prejudicaram ainda mais. Depois de cada interrupção no tratamento, cerca de duas vezes em que a família fugiu da favela por conta das ameaças que sofriam pelo tráfico, o comportamento de Paulo ganhava tons variados, como os furtos, os roubos, o vestir-se e comportar-se como menina, uma verdadeira defesa contra todo o horror pelo qual passou, expressando, dessa forma, sua dor e desamparo emocionais. Ele escutava sempre da mãe e da avó que seria como o pai, um marginal condenado à morte, que era muito parecido fisicamente com o pai e carregava seu nome. São mensagens ameaçadoras, que o intimaram subjetivamente a procurar uma saída para não enlouquecer. Esses são fatores que contribuíram para que Paulo passasse a ser Paula.

Lembremos que, na teoria de Winnicott, quando a mãe falha continuamente o que ocorre é o soerguimento de defesas contra as falhas ambientais em algum momento das fases do desenvolvimento emocional primitivo, tentando se proteger das falhas ambientais. Nos casos analisados, o que verificamos foi uma impossibilidade de ambas as famílias darem continuidade aos cuidados necessários durante a fase da dependência relativa a esses meninos. Por exemplo, para Paulo, ter sido obrigado a assistir a brutal morte de seu pai foi um acontecimento traumático. Quando Paulo vivenciou essa perda, ele sofreu danos severos em sua identidade, impulsividade, espontaneidade e possibilidade de criatividade. Nas sessões era comum ouvir:

"Nem lembro do meu pai tia, me fala, para que eu vou lembrar? Ele não me ajudou em nada mesmo, dizem que morreu porque não prestava, bem feito, tinha que ter morrido mesmo!". E Jonas ao dizer: "Tia, eu odeio meu pai, ele só faz maldade comigo e com minha mãe, eu não aguento mais apanhar todo dia, todo dia é surra".

Para Paulo, a figura do pai acolhedor misturou-se a um ambiente avassalador, aterrorizante, de morte e medo. Para Jonas, pelo contrário, era a figura de pai que lhe causava dor e angústia, malgrado tenha recebido atenção, afeto, carinho e cuidado da mãe. Em termos parentais, o pai alcoolizado nunca sustentou um lugar continente, oferecendo confiabilidade e segurança, sendo apenas, na verdade, uma real violência.

Ambos, quando estavam nas sessões terapêuticas ou nas atividades do Circo Social, começaram a experimentar uma relação semelhante a que o bebê vive com sua "mãe objeto" (Winnicott, 1975), ou seja, 
testando o ambiente psicoterápico, da mesma forma que testavam o ambiente do Circo Social, atacando-os, agredindo a psicoterapeuta, as assistentes sociais ou os professores do Circo. Testavam o setting e o ambiente do Circo de igual modo, por meio do seu amor cruel (ruthlessness) (Winnicott, 1978d). O que precisa ser destacado é que tanto a psicoterapeuta (assim como os outros integrantes da equipe), quanto o ambiente do Circo, precisaram suportar seus ataques.

Ora, em "Variedades da psicoterapia" Winnicott (2005) já havia afirmado que nem sempre a psicoterapia é suficiente para o atendimento de crianças ou adolescentes com tendência ou comportamento antissocial. Pelo contrário, a constituição de um lar ou um ambiente acolhedor e suficientemente bom é necessária e parte coadjuvante do tratamento. Esse ambiente, em nosso trabalho, foi constituído pela equipe interdisciplinar com os cuidados fornecidos pela equipe de assistentes sociais, pela equipe de psicologia clínica e pelos pedagogos em suas atividades do "Circo Social".

O assistente social surge como uma tentativa de fornecer profissionalmente a ajuda que seria propiciada não profissionalmente pelos pais, pelas famílias e por unidades sociais. Ele não é um psicoterapeuta, mas se constitui como um psicoterapeuta quando atende casos de comportamento antissocial, sustentando a função parental e de unidades sociais (Winnicott, 1961, p. 269). Do mesmo modo, as atividades do pedagogo e do Circo Social, forneceram um ambiente lúdico e criativo quando este ambiente não foi totalmente encontrado em casa com os seus pais. Assim, o processo de socialização da criança ou adolescente inserido dentro do "projeto", com o atendimento clínico e dentro das atividades do "Circo", surge como espaços onde elas puderam vivenciar situações de acolhimento e cuidado, ou, como diz Winnicott:

A psicoterapia destinada a tratar de uma tendência antissocial num paciente só funciona como eu disse, se o paciente estiver perto do começo de sua carreira antissocial, antes de se estabelecerem ganhos secundários e habilidades delinquentes. Somente nos estágios iniciais é que o paciente sabe que é um paciente e sente, realmente, a necessidade de chegar às raízes da perturbação. Quanto o trabalho é possível de acordo com essa orientação, o médico e o paciente preparam-se para desfiar uma espécie de história policial, usando todas as pistas que possam existir, inclusive o que é conhecido da história passada do caso, e o trabalho é feito numa fina camada que se situa em algum lugar entre o inconsciente profundamente enterrado e a vida consciente e o sistema mnêmico do paciente (Winnicott, 2005, p. 272-273). 
No caso de Jonas e Paulo, isso é totalmente verdadeiro. A confiança no mundo externo para essas crianças foi testada por meio da destruição e aniquilamento dos objetos externos que os cercam - o Circo e a figura da psicoterapeuta, para que assim pudessem realmente confiar nesse mundo. Paulo e Jonas estavam, na verdade, começando a experiência de se sentirem reais e de existirem pela primeira vez na vida, e seu pedido de socorro precisava ser reconhecido para que eles finalmente encontrassem um ambiente seguro e confiável.

Paulo, além de roubar, também agredia seus pares e, em determinado momento, até a própria psicoterapeuta e o Circo. Essa criança necessitava da disponibilidade pessoal da psicoterapeuta em acolher suas exigências com tolerância e sem retaliação, revelando, assim, a consistência do seu amor por ele. Jonas, por sua vez, tentava manter essa relação mais preservada com a psicóloga, embora um dia tenha trazido para o atendimento uma arma. A maneira de Jonas testar o ambiente era trazendo o que representava sua força diante dos outros, e principalmente em relação ao pai, já que era um soldado armado do tráfico.

A origem de toda delinquência e violência que foram encontradas nas experiências de Paulo, assim como, a experiência de deprivação relativas às etapas iniciais do seu desenvolvimento, se constituíram na relação às falhas dos cuidados maternos, e da provisão advinda do pai. O pai representa a sociedade, precisava ser carinhoso e forte, muitas vezes severo com a criança e impondo limites. Na relação com a mãe, encontrava a expressão no roubo, que aponta para a experiência de uma deprivação em um momento anterior à explosão agressiva.

A provisão dos limites paternos, no entanto, está diretamente relacionada ao desenvolvimento das moções agressivas e destrutivas. Porém, a tendência antissocial aponta para a existência de uma deprivação que não pode ser superada sem um suporte terapêutico e a provisão de um ambiente, tal como um lar substituto. Nas crianças estudadas, esse ambiente foi constituído pelo trabalho realizado pelo Circo em conjunto com o processo psicoterápico, assim como, o trabalho dos demais membros da equipe. As defesas ficaram rigidamente estabelecidas, agravadas por ganhos secundários, como por exemplo, os roubos. Ela necessita ser prontamente atendida em seus apelos desesperados por socorro e por uma provisão ambiental adequada. Quanto mais rápidas e eficientes forem essas respostas, maiores serão as chances de recuperação.

Necessitamos, enquanto psicoterapeutas, buscar compreender o que realmente se passava com a criança no momento em que o ambiente seguro e confiável não mais se constitui durante a fase da dependência relativa, uma vez que essa compreensão irá envolver diretamente suas relações parentais e familiares. Somente assim 
poderemos começar a construir acessos para um tratamento psicoterápico viável e para a compreensão de suas vicissitudes.

Um tratamento como o de Paulo exigia tempo e, principalmente, disponibilidade da terapeuta em suportar suas agressões. Paulo precisava manter a esperança de encontrar alguém com quem pudesse estabelecer uma relação estável e segura, que servisse como meio (ambiente) para que ele pudesse experimentar o incomensurável sofrimento que vivenciou na época da deprivação. Para tanto, ele precisava se deparar com uma psicoterapeuta humana, demasiadamente presente e contínua (continente), e que poderia até mesmo falhar nos atendimentos, oferecendo-lhe pequenas doses de frustração, tal qual a mãe na fase do início da dependência relativa. Neste caso, a infalibilidade pertence às máquinas, diz Winnicott (1968), e o que essas crianças precisavam era de um ambiente profundamente humano.

Segundo Winnicott (2000c), o terapeuta precisa falhar, assim como a mãe, mas a continuidade do tratamento é condição sine qua non para que o trabalho de restabelecimento da confiança no ambiente aconteça. Aqui, o ambiente falhou de novo. E de novo. Para que sua trajetória psíquica pudesse ter sido diferente, teria sido necessário que houvesse uma aposta por parte da família, nele e no tratamento, o que não aconteceu. As muitas formas de sabotagem da família aos atendimentos eram percebidas inconscientemente pela criança como mais uma forma de ataque à sua saúde mental. Paulo ficou sendo o representante de toda a violência trágica sofrida pela família. Esse veredicto, confirmado pela escola, inviabilizou a permanência de Paulo, mesmo sendo Paula ${ }^{a 5}$. Para não ter o mesmo destino que seu pai, ele teve que ser outra pessoa.

O comportamento antissocial de Jonas e Paulo constitui uma esperança. Levisky (2011) aponta que a criança pode roubar até mesmo pela tentação de possuir o objeto, porém, o roubo tem um significado inconsciente; ele é na realidade uma tentativa de resgate da capacidade de buscar o que lhe falta ou o que lhe foi tirado: o amor e o afeto dos pais. Eles então tentam buscar em outros objetos - Paulo nos roubos e Jonas como soldado - uma reação que Ihes dará sentido de existir.

Um ponto importante para Jonas era como ser aceito no tráfico como um adulto e não como uma criança. Assumir precocemente a posição de homem era libertar-se de estar ao arbítrio da ilusória proteção de seus pais. Como um homem, podia modificar aquele ambiente; como uma criança, nada podia fazer. Trabalhar no tráfico era a maneira de se tornar proprietário de sua liberdade e de dar um sentido para a sua vida, com benefícios materiais e afetivos (Levisky, 2011).

Por muitos momentos, as atividades propostas no projeto, bem como os encontros entre mãe e filho nas sessões psicoterápicas com a família foram dirigidas para que Jonas e a mãe pudessem sentir o 
contato próximo, tocando-se nas brincadeiras, tal como visto no jogo "tapete colorido". Neste jogo, um tapete de plástico de grandes dimensões é colocado no chão como um tabuleiro. Ele tem quatro linhas de grandes círculos coloridos, cada um com uma cor diferente em cada linha: vermelho, amarelo, azul e verde. Um ponteiro é anexado a um tabuleiro dividido em quatro seções rotuladas: pé direito, mão esquerda, pé esquerdo e mão direita. Cada uma dessas quatro partes também é dividida nas mesmas cores acima. Após girar o ponteiro, se dá uma combinação (por exemplo: amarelo da mão direita) e os jogadores devem mover a mão ou o pé correspondente a um círculo da cor correta. Em um jogo de dois jogadores, duas pessoas não podem ter uma mão ou um pé sobre o mesmo círculo. Quando mãe e filho puderam experimentar esse jogo, ambos tinham que se posicionar de acordo com as peças e cores definidas para mãe e filho e, a cada rodada, eles se abraçavam. No momento em que acertavam alguma pergunta, vibravam felizes por terem, unidos, conseguido realizar a atividade proposta pelo jogo. Esses momentos eram puras experiências de mutualidade vividas na relação mãe e filho.

A ênfase, aqui, repousa na experiência de continuidade de ser e no enriquecimento do sentimento de self significativos na relação afetuosa e de intimidade da mãe com Jonas e dele com sua mãe. $O$ jovem, então, podia se sentir integrado, capacitado subjetivamente a realizar uma ação criativa, tal como levar sua mãe no colo para colocá-la na cadeira de rodas nos momentos em que as sessões psicoterapêuticas com os familiares iniciavam ou terminavam. Jonas comprou a cadeira com o dinheiro da bolsa do Projeto.

"Eu acho que meu filho me ama, porque eu amo muito ele, mas eu não sei falar direito. Ele é um menino bom, só precisava da senhora [terapeuta] e de um lugar pra ficar longe do tráfico, isso aqui salvou meu filho".

Ele estava vivo na relação com a mãe, e isso era positivamente significante para a melhoria de sua vida interna, e consequentemente, para a diminuição do comportamento delinquente, um verdadeiro escudo contra o ambiente aterrorizador que o rodeava.

No caso de Paulo, as inúmeras tentativas através de visitas realizadas pelo serviço social do projeto, ora com a assistente social, ora com a ida da própria psicóloga nessas visitas, era uma tentativa de estabelecermos um elo com a família. Porém, todas essas visitas (seis ao todo) pelo serviço social e duas pela psicóloga foram frustradas. A família se esquivava, sempre demonstrando a sua impossibilidade de atender às necessidades de Paulo e de reconhecer a importância de estar acompanhando de forma presencial os 
atendimentos. Por isso suas constantes fugas do processo psicoterápico. Como conquistar um ambiente de confiança e de acolhimento, se esse mesmo ambiente que ele encontrava em casa, retalhava as tentativas de aproximação entre a equipe e a sua família?

Winnicott (2000b) é enfático ao dizer que não é apenas a psicanálise que estabelecerá mudanças significativas, mas a provisão de um ambiente especializado, que possua um objetivo terapêutico, capaz de dar uma resposta à altura das suas necessidades.

Todas as tentativas de trazê-lo de volta para atendimento foram fracassadas. Paulo transformara-se em Paula, e como tal, chegou a agredir tanto a psicoterapeuta quanto a assistente social, cuspindoIhes no rosto e afirmando: "agora vocês não vão mandar em mim, e eu vou ser quem eu quiser. Tia, eu odeio o Circo!".

Transformar-se em Paula foi a forma encontrada por Paulo para sobreviver a um ambiente acolhedor que em algum momento fracassou. Esse comportamento remete-nos a uma tentativa de se proteger de um mundo externo hostil e agressivo. Ele não teve a oportunidade de se encontrar no olhar, no toque e no gesto amoroso da mãe, conforme descreve Winnicott (1975) em seu texto "O papel de espelho da mãe e da família no desenvolvimento infantil". O rosto dela não refletiu o seu rosto, ou talvez este espelhado tenha se constituído como um reflexo de tudo o que Paulo queria ser para poder sobreviver - ser amado/amada. Ser Paula, pensamos, tornouse a única saída criativa para sobreviver à falta desse amor, por meio de uma personalidade do tipo falso self (Paulo/Paula) e protegendo o seu verdadeiro self. Para Winnicott (2005), o falso self se submete ao ambiente como forma de proteger o verdadeiro self e isso se inicia nas primeiras etapas do desenvolvimento emocional, mas também pode se constituir ao longo das demais etapas do desenvolvimento como uma tendência antissocial.

Para Winnicott (2000b), o tratamento para uma tendência antissocial se dá por meio de um ambiente amoroso e firme, apesar dessas crianças carregarem as cicatrizes desse sofrimento. Elas sobreviveram às adversidades impostas pela vida, mas não as esquecem. Mas como esperar dessas crianças que sofreram tamanhas dores advindas de casa, da escola, da realidade da favela, que conseguissem sozinhas encontrar forças para lidar com os limites que a sociedade impõe, sem transgredi-los? Eles tiveram suas vidas marcadas por sofrimento, provisão ambiental falha e inúmeras dificuldades de acesso aos seus direitos básicos.

Para Paulo, a continuidade do tratamento foi impedida. No entanto, mantemos a esperança de que algo da experiência de acolhimento seguro, afetuoso, tenha permanecido em sua memória como registro de que no mundo não há somente violência. Assim como no Circo, 
onde pôde experimentar, ainda que por momentos breves, a alegria de ser uma criança.

O encontro psicoterapêutico para J onas configurou-se como o espaço potencial onde pôde começar a experimentar a criação do seu mundo, a partir da confiança, uma vez que o indivíduo passa a sentirse real e também a sentir o mundo como algo menos ameaçador, com o qual é possível se relacionar e onde a vida vale a pena ser vivida.

\section{Considerações finais}

As crianças e adolescentes com as quais trabalhamos tiveram a violência destroçando suas vidas, que ficaram inexoravelmente marcadas. Crianças que tiveram que lidar com as leis do tráfico de drogas, e com as arbitrariedades da polícia, que teria a obrigação de Ihes proteger. Famílias que tiveram suas vidas ameaçadas por bandidos e/ou por policiais, que aprenderam a ter medo de lutar por seus direitos. Vimos, então, que os sintomas antissociais significam tentativas de recuperação ambiental e indicam esperança. A criança antissocial necessita, portanto, de um ambiente especializado que possua um objetivo terapêutico claro e bem definido. Ambiente que seja capaz de dar uma resposta fundamentada na realidade à esperança que se expressa por meio dos sintomas. Winnicott (2011) nos aponta que isso precisa ser feito por um período longo, cuidadoso, para que possa ser eficaz como tratamento, e em outro momento, aponta:

Se há as chamadas "famílias-problemas", não se pode culpar inteiramente a autoridade local pelas condições de favelas em que a criança é cuidada. O cuidado físico é afetado pela capacidade das crianças ou pais de recebe-lo e se verifica que ao redor da área a que chamamos de cuidado físico há o território complexo dos distúrbios emocionais do indivíduo, de grupos de indivíduos ou da sociedade (Winnicott, 1983b, p. 63).

Winnicott entende que a criança que sofreu deprivação é uma pessoa com uma história passada de experiências traumáticas, e com um modo pessoal de enfrentar as ansiedades despertadas por sua história. Ela tem a possibilidade de se recuperar, dependendo do grau de perda de consciência, do ódio e da capacidade primária para amar. Mas as marcas continuam.

Paulo, por não ter encontrado um ambiente onde pudesse se sentir amado e acolhido, não conseguiu sozinho e, nem com a ajuda da terapeuta, ter a possibilidade de uma vida com menos dor. Não há 
possibilidade de mudança na vida de qualquer criança, quando a família não a sustenta emocional e fisicamente, a marginaliza e ignora o tempo todo. Podemos afirmar, com Winnicott, que o incômodo causado pelo comportamento da criança antissocial tem um valor que é positivado para o seu pedido de ajuda em relação à sociedade. É uma característica favorável que indica a presença da potencialidade de recuperação da fusão dos impulsos instintuais e da motilidade. Deixamos a pergunta: será que ainda há esperanças para ele?

Embora essa mudança de identidade tenha sido uma saída radicalmente defensiva com relação às situações traumáticas, sabemos que a adolescência é um momento de (re)significação de muitos conflitos. Mesmo considerando o quadro de falhas na vida dessas crianças no curso do seu desenvolvimento, podemos ter a esperança de que a relação de confiança que estabeleceu com a terapeuta sirva de referência para uma possível retomada de outro vínculo terapêutico. Jonas transcendeu o sofrimento, conseguiu o direito de ser uma pessoa respeitada e se sentir real. Conseguiu ter esperança na vida e senti-la como digna de ser vivida.

$\mathrm{O}$ projeto social se tornou um ambiente suficientemente bom que permitiu a Paulo e Jonas reescrever suas vidas, por meio da criatividade e da esperança. Uma provisão ambiental adequada, tanto nos atendimentos do serviço de psicologia, quanto no Circo, foram o holding, o acolhimento e o continente para esses jovens, a luz no fim do túnel para esse universo de sobreviventes da realidade violenta.

\section{Referências}

Abram, J. A.(2000.) A linguagem de Winnicott. Rio de Janeiro: Revinter.

Alves, M. H. M., \& Evason, P. (2013). Vivendo no fogo cruzado: Moradores da favela, traficantes de droga e violência policial no Rio de Janeiro. São Paulo: Editora UNESP.

Batista, V. M. (2003). O medo na cidade do Rio de Janeiro: Dois tempos de uma história. Rio de Janeiro: Revan.

Bogomoletz, D. (2008). Winnicott - Paixão, compaixão e humor: Para uma teoria Winnicottiana da delinquência. Redepsi, 3(23), 3647.

Burgos, B. M., Pereira, L. F. A., Cavalcanti, M., Brum, M., \& Amoroso, M. (2011). O efeito da UPP na percepção dos moradores das favelas. Desigualdade \& Diversidade - Revista de Ciências Sociais da PUC-Rio, 11, 49-98.

Levinsky, L. D. (2011). Tendências Antissociais: Teorias e práticas preventivas a partir do conceito de espaço transicional. In 
Sucar, I. \& Ramos, H. (Org.). Winnicott - Ressonâncias (pp. 313-325). São Paulo: Primavera Editorial.

Machado da Silva, L. A., \& Leite, M. P. (2007). Violência, crime e política: o que os favelados dizem quando falam desses temas? Sociedade e Estado, Brasília, 22(3), 545-591.

Paiva, R. L. S. (2014). Da sombra da violência à luz no fim do túnel: As vicissitudes de crianças de uma favela carioca. Dissertação de Mestrado, Pontifícia Universidade Católica do Rio de Janeiro, Rio de Janeiro, RJ, Brasil.

Rios, J. A. (2012). Aspectos humanos das favelas cariocas - 50 anos: Uma avaliação. In: Mello, M. A. S. \& Silva, L. A. M. (Org.). Favelas Cariocas ontem e hoje. Rio de Janeiro: Garamond.

Silva, L. A. M. (2009). Vida sob cerco. Violência e Rotina nas Favelas do Rio de Janeiro. Rio de Janeiro: Nova Fronteira.

Silva, S. G. (2010a). Direitos humanos: entre o princípio da igualdade e a tolerância. Revista Praia Vermelha, 19(1), 79-94.

Silva, S. G. (2010b). Preconceito e discriminação: as bases da violência contra a mulher. Psicologia, Ciência e Profissão, 30(3), 556-571.

Silva, S. G. (2003). Preconceito no Brasil contemporâneo: as pequenas diferenças na constituição das subjetividades. Psicologia, Ciência e Profissão, 23(2), 2-5.

Vilhena, J., \& Maia, M. V. C. (2002). Agressividade e violência: reflexões acerca do comportamento antissocial e sua inscrição na cultura contemporânea. Revista Mal-Estar e Subjetividade, 2(2), 27-58.

Vilhena, J., Bittencourt, M. I., Zamora, M. H., Novaes, J. V., \& Bonatto, M. (2011). Medos infantis, cidade e violência: expressões em diferentes classes sociais. Psicologia Clínica, 23(2), 171-186.

Winnicott, D. W. (1987). The Piggle: Relato do tratamento psicanalítico de uma menina. Rio de Janeiro: Imago. (Trabalho original publicado em 1977).

Winnicott, D. W. (2000a). O desenvolvimento emocional primitivo. In: D. W Winnicott (Org.). Textos Escolhidos: Da pediatria à psicanálise (pp. 218-232). Rio de Janeiro: Imago. (Trabalho original publicado em 1945).

Winnicott, D. W. (2000b). Retraimento e Regressão. In: D. W Winnicott (Org.). Textos Escolhidos: Da Pediatria à Psicanálise (pp. 347-354). Rio de Janeiro: Imago Editora. (Trabalho original publicado em 1954).

Winnicott, D. W. (2000c) A tendência antissocial. In: D. W Winnicott (Org.). Textos Escolhidos: Da Pediatria à Psicanálise (pp. 406416). Rio de Janeiro: Imago Editora. (Trabalho original publicado em 1956). 
Winnicott, D. W. (2005). Raízes da Agressão. In: D. W Winnicott (Org.). Privação e delinquência (pp. 102-110). São Paulo: Martins Fontes. (Trabalho original publicado em 1964).

Winnicott, D. W. (2011). A delinquência como sinal de esperança. In: D. W Winnicott (Org.). Tudo começa em casa (pp. 81-91). São Paulo: Editora Martins Fontes. (Trabalho original publicado em 1967).

Winnicott, D. W. (1983a). Teoria do relacionamento paterno-infantil. In: D. W Winnicott (Org.). O ambiente e os processos de maturação: estudos sobre a teoria do desenvolvimento emocional (pp. 38-54). Porto Alegre: Artmed. (Trabalho original publicado em 1960).

Winnicott, D. W. (1983b). Provisão para a criança na saúde e na crise. In: D. W Winnicott (Org.). O ambiente e os processos de maturação: estudos sobre a teoria do desenvolvimento emocional (pp. 62-69). Porto Alegre: Artmed. (Trabalho original publicado em 1962).

Winnicott, D. W. (1978a) Psicose e cuidados maternos. In: D. W Winnicott (Org.). Textos Escolhidos: Da Pediatria à Psicanálise (pp. 375-387). Rio de Janeiro: Francisco Alves. (Trabalho original publicado em 1952).

Winnicott, D. W. (1978b). Ansiedade associada à insegurança. In: D. W Winnicott (Org.). Textos Escolhidos: Da Pediatria à Psicanálise (pp. 205-210). Rio de Janeiro: Francisco Alves. (Trabalho original publicado em 1952).

Winnicott, D. W. (1978c) Pediatria e psiquiatria In: D. W Winnicott (Org.). Textos Escolhidos: Da Pediatria à Psicanálise (pp. 287311). Rio de Janeiro: Francisco Alves. (Trabalho original publicado em 1948).

Winnicott, D. W. (1978d). A posição depressiva no desenvolvimento emocional normal. In: D. W Winnicott (Org.). Textos Escolhidos: da pediatria à psicanálise (pp. 437-458). Rio de Janeiro: Francisco Alves. (Trabalho original publicado em 1954).

Winnicott, D. W. (1994). Nada no centro. In: D. W Winnicott (Org.). Explorações Psicanalíticas (pp. 41-43). Porto Alegre: Artmed. (Trabalho original publicado em 1959).

Winnicott, D. W. (2005). Variedades da Psicoterapia. In: D. W Winnicott (Org.). Privação e delinquência (pp. 263-273). São Paulo: Martins Fontes. (Trabalho original publicado em 1961).

Winnicott, D. W. (1975). O papel de espelho da mãe e da família no desenvolvimento infantil. In: D. W Winnicott (Org.). O brincar e a realidade (pp. 153-162). Rio de Janeiro: Imago. (Trabalho originalmente publicado em 1967).

Winnicott, D. W. (2006). A comunicação entre o bebê e a mãe e entre a mãe e o bebê: convergências e divergências. In: $D$. W 
Winnicott (Org.). Os bebês e suas mães (pp. 79-92). São Paulo: Martins Fontes. (Trabalho originalmente publicado em 1968).

\section{Endereço para correspondência \\ Rosa Lucia Soares Paiva}

Curso Aprimore

Departamento de Psicologia

Rua Rodrigo Silva, 34ạ , 3o andar, Centro, CEP 20011-040, Rio de Janeiro - RJ, Brasil

Endereço eletrônico: profrosalucia@gmail.com

Maria Helena Rodrigues Navas Zamora

Pontifícia Universidade Católica do Rio de Janeiro

Departamento de Psicologia

Laboratório Interdisciplinar de Pesquisa e Intervenção Social - LIPIS

Rua Marques de São Vicente, 225, Gávea, CEP 22453-900, Rio de Janeiro - RJ, Brasil

Endereço eletrônico: zamoramh@gmail.com

\section{J unia de Vilhena}

Pontifícia Universidade Católica do Rio de Janeiro

Departamento de Psicologia

Laboratório Interdisciplinar de Pesquisa e Intervenção Social - LIPIS

Rua Marques de São Vicente, 225, Gávea, CEP 22453-900, Rio de Janeiro - RJ, Brasil

Endereço eletrônico: vilhena@puc-rio.br

\section{Sergio Gomes da Silva}

Universidade Federal do Rio de Janeiro

Instituto de Psicologia

Divisão de Psicologia Aplicada Profa. Isabel Adrados

Av. Pasteur, 250, Fundos, Praia Vermelha, CEP 22290-240, Rio de Janeiro - RJ, Brasil

Endereço eletrônico: sergiogsilva@uol.com.br

Recebido em: 16/06/2014

Reformulado em: 06/06/2015

Aceito para publicação em: 08/06/2015

\section{Notas}

* Mestre em Psicologia Clínica - PUC-Rio. Especialista em Psicopedagogia Clinica e Institucional pela UNESA, Gestora deo Projetos pela Fundação Getúlio Vargas e colaboradora do Laboratório Interdisciplinar de Pesquisa e Intervenção Social LIPIS da PUC-Rio.

** Doutora em Psicologia Clínica - PUC-Rio; Professora do Programa de PósGraduação em Psicologia Clínica da PUC-Rio; Vice-Coordenadora do Laboratório Interdisciplinar de Pesquisa e Intervenção Social - LIPIS da PUC-Rio.

*** Doutora em Psicologia Clínica - PUC-Rio, Profa. do Programa de Pós-Graduação em Psicologia Clínica da PUC-Rio, Coordenadora do Laboratório Interdisciplinar de Pesquisa e Intervenção Social - LIPIS da PUC-Rio, Pesquisadora correspondente do Centre de Recherches Psychanalyse et Médecine, CRPM-Pandora - Université DenisDiderot Paris VII.

**** Doutor em Psicologia Clínica-PUC-RIO; Supervisor de Estágio da Divisão de Psicologia Aplicada Professora Isabel Adrados/Instituto de Psicologia/UFRJ; Psicanalista e Membro Associado em Formação do Círculo Psicanalítico do Rio de Janeiro. 
${ }^{1}$ Doravante chamaremos a favela onde o trabalho foi desenvolvido de "Morro"; os atendimentos psicoterapêuticos realizados dentro do Projeto Circo Social de "Projeto" e as atividades circenses da equipe de "Circo".

2 Apesar do termo "deprivação" (deprivation) tratar-se de um anglicismo, ou seja, a incorporação de um termo da língua inglesa à língua portuguesa, a maior parte dos autores e comentadores que trabalham com as referências teóricas de Winnicott adotam o termo "deprivação" em oposição à "privação" (privation ou deprivation) para se referir às falhas ambientais presentas no segundo período do desenvolvimento emocional, qual seja, a dependência relativa, conforme aponta Abram (2000).

${ }^{3} \mathrm{O}$ namorado mais velho que Paulo se referia, era um dos meninos que andavam com ele dentro da favela, um menino de 12 anos. Não sabemos ao certo a fidedignidade do fato, apesar de ter sido pela equipe investigado, os rumores dentro da favela eram que esse "homem" morava em outra favela da região, e comportava-se como um soldado do trafico, apesar de isso também ter sido negado em conversas com os moradores da favela.

${ }^{4}$ Apesar de o paciente apresentar um comportamento feminino, intitulando-se de "Paula", manteremos o gênero masculino em todas as suas referências por acreditarmos que o caso não se trata de uma questão relacionada à identidade de gênero, e sim, a forma criativa com a qual o paciente precisou se constituir diante do seu sintoma.

${ }^{5} \mathrm{O}$ nome verdadeiro de Paulo não tem o correspondente feminino. Ou seja, a mudança de identidade masculina para feminina promoveu, inclusive, a escolha de um outro nome. Foi, portanto radical a defesa usada por Paulo.

Esta Pesquisa teve o financiamento da CAPES em parceria com PUC-Rio. Com una bolsa de estudos subsidiando o mestrado de Rosa Lucia Soares Paiva. 